\title{
Stability assessment of initial shotcrete lining using two-dimensional continuum numerical modelling
}

\author{
S Naseri Dalhousie University, Canada \\ N Bahrani Dalhousie University, Canada
}

\begin{abstract}
The convergence-confinement method (CCM) is a simple tool for the preliminary design of ground support for circular excavations. The influence of excavation advance rate on the design of a support system is often ignored using the CCM. In this paper, a two-dimensional (2D) continuum numerical modelling approach for support design is introduced, which integrates the excavation advance rate into the CCM. The numerical simulations are carried out based on the results of a previously calibrated $2 D$ finite element model of an instrumented section of a $10 \mathrm{~m}$ diameter shaft in an average-quality rock mass. First, the internal pressure reduction approach is used to simulate the three-dimensional shaft advance and to generate the ground reaction curve (GRC). The longitudinal displacement profile (LDP) is calculated using a semi-empirical approach. The LDP is then integrated with the GRC to determine the radial displacements corresponding to the locations of the shaft face and initial shotcrete liner. Knowing the shaft advance rate allows determination of the appropriate mechanical properties of early-age shotcrete based on empirical equations. The paper presents three approaches for analysing the stability of the shotcrete liner. The first approach is based on calculating the load Factor of Safety using support-capacity diagrams. In the second approach, the load Factor of Safety is calculated using the conventional CCM. In the third approach, the strain Factor of Safety is calculated by considering the plastic deformation of early-age shotcrete. The minimum allowable shotcrete thickness is then determined by calculating the load and strain Factors of Safety for different lining thicknesses. It is suggested that a combination of these approaches provides a deeper insight into the complex behaviour of early-age shotcrete lining during excavation advance compared with the conventional CCM.
\end{abstract}

Keywords: initial shotcrete lining, convergence-confinement method, ground reaction curve, longitudinal displacement profile, 2D numerical modelling, support-capacity diagram, strain Factor of Safety

\section{Introduction}

Shotcrete is widely used as a support element in the construction of underground mines and tunnels. The initial shotcrete is sprayed close to the excavation face to accommodate inward radial displacements prior to the installation of a final, permanent lining. It also provides rapid full-areal support to advancing excavations by holding up small and large pieces of rock. Therefore, the ability of initial shotcrete lining to resist falls of ground is of paramount importance. Today, the time for re-entry into a shotcreted heading is typically around 30-120 minutes (Rispin et al. 2017). For this reason, the design of the initial shotcrete lining should be based on the mechanical properties of early-age shotcrete.

The properties of early-age shotcrete change progressively as the excavation face advances. This should be taken into consideration when designing the initial shotcrete lining. In this regard, Oreste \& Pelia (1997) and Oreste (2003) developed a methodology for determining the characteristic curve of shotcrete lining as a function of the excavation advance rate by considering the changes in the shotcrete stiffness with time. Gschwandtner \& Galler (2012) demonstrated the influence of the excavation advance rate on the time-dependent properties of shotcrete (i.e. strength and Young's modulus) and its Factor of Safety.

Following the application of shotcrete to the excavation boundary, not only does the shotcrete gain strength and stiffness but it may also be subject to plastic deformation if it is loaded beyond its maximum capacity (John \& Mattle 2003). This means that early-age shotcrete linings can sustain the ground load while 
undergoing plastic deformation before failure occurs. This aspect should also be considered when designing the initial shotcrete lining, particularly in fast-advancing excavations.

This paper reports on the use of a two-dimensional (2D) continuum numerical model to simulate the three-dimensional (3D) advance of a $10 \mathrm{~m}$ diameter shaft in an average-quality rock mass. The rock mass properties used in the numerical model were obtained from a previously calibrated finite element model of an instrumented section of the shaft at a depth of $1.2 \mathrm{~km}$. The calibrated model was then used to simulate shotcrete linings of various thicknesses and to investigate their response to the shaft advance and associated wall convergence using support-capacity diagrams. A procedure for determining the strain Factor of Safety for early-age shotcrete lining is introduced and the results are compared with the load Factor of Safety. It is suggested that a combination of load and strain Factors of Safety provides a better understanding of the complex behaviour of early-age shotcrete lining during excavation advance.

\section{Convergence-confinement method}

The convergence-confinement method (CCM) is a tool for anticipating the level of ground deformation along the boundary of an advancing circular excavation (e.g. tunnel or shaft) and support design. The CCM uses a simple 2D approach to capture 3D effects of an advancing excavation. During the excavation advance, the face acts as a support that carries a portion of the load (called 'face effect'). This allows for the excavation boundary behind the face to accommodate the rest of the load. As the excavation advances, the face effect gradually diminishes, thus causing the excavation boundary well away behind the face to carry all the load. At this stage, the maximum inward displacement of the excavation boundary occurs. By considering the use of a support element installed at a distance behind the tunnel face, it is possible to calculate the support Factor of Safety knowing the support capacity and the ground pressure.

The CCM is applicable to cases where the in-situ stress field is hydrostatic, the rock mass is homogeneous, and the excavation shape is circular. It consists of three components: the ground reaction curve (GRC), the longitudinal displacement profile (LDP) and the support characteristic curve (SCC). Figure 1a shows the longitudinal section of an advancing tunnel and the radial displacement profile along the tunnel boundary. The following provides a brief description of each component.

The GRC represents the progressive advance of a circular excavation. It provides a relationship between the internal pressure $\left(P_{i}\right)$ and the radial displacement $\left(U_{r}\right)$ of the excavation boundary (Figure $1 \mathrm{~b}$ ). In the GRC, it is assumed that an internal pressure, equal to the magnitude of far-field in-situ stress $\left(P_{0}\right)$, is applied in the opposite direction to the excavation boundary $\left(P_{i}=P_{0}\right)$ at a distance well ahead of the excavation face, where there is no face effect (section A-A' in Figure 1a). As the excavation advances (to the left in Figure 1b), the radial displacement gradually increases due to the progressive reduction of the internal pressure. At the excavation face, some of the ground pressure is carried by the face $\left(P_{i}<P_{0}\right.$ in Figure $\left.1 a\right)$, and the rest is transferred to the excavation boundary behind the face. At a distance well behind the face (section $B^{-} B^{\prime}$ in Figure 1a) where there is no face effect, the internal pressure is zero and the excavation boundary converges to its final radial displacement (maximum closure, $U_{r-m a x}$ ). The GRC can be obtained using closed-form solutions (e.g. Carranza-Torres 2004; Duncan Fama 1993) or 2D continuum modelling (e.g. Vlachopoulos \& Diederichs, 2014).

The LDP represents the radial displacement of the excavation boundary as a function of distance from the face inside the excavation (behind the face) and in the rock mass (ahead of the face) (Figure 1[c]). When a circular opening is excavated, it starts to converge radially ahead of the excavation face due to the redistribution of in-situ stresses. It is known that the radial displacement at the excavation face is about $30 \%$ of its maximum value at a distance well behind the face, where there is no face effect. As the excavation face advances, the inward displacement gradually increases and eventually reaches its maximum value at a distance well behind the face. By combining the GRC and the LDP, it is possible to identify the radial displacement on the GRC corresponding to the excavation face (see tunnel face on the GRC in Figure 1b). The LDP can then be used to determine the radial displacement corresponding to a distance behind the face where the ground support is installed (Figure $1 \mathrm{~b}$ ). 
a)

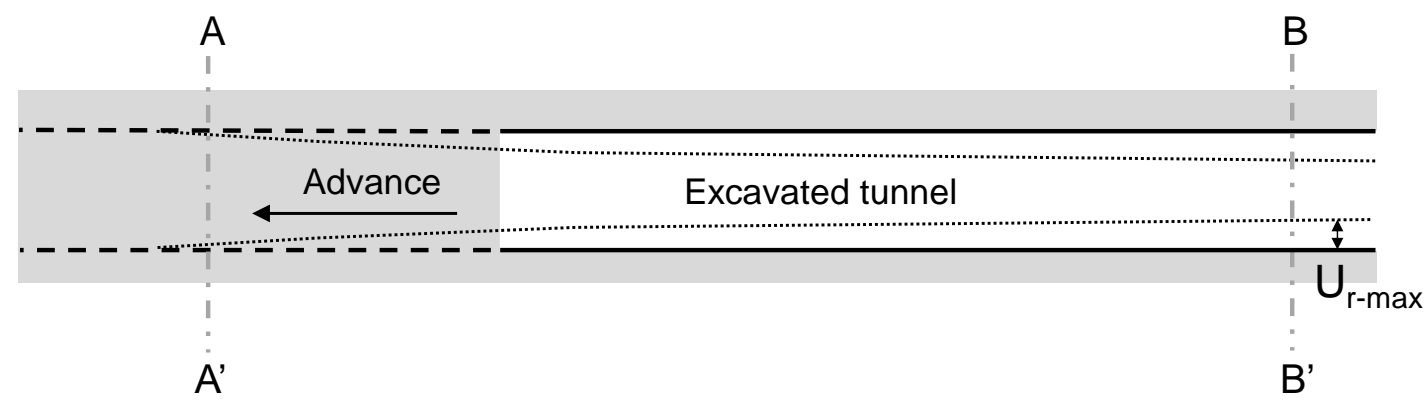

b)
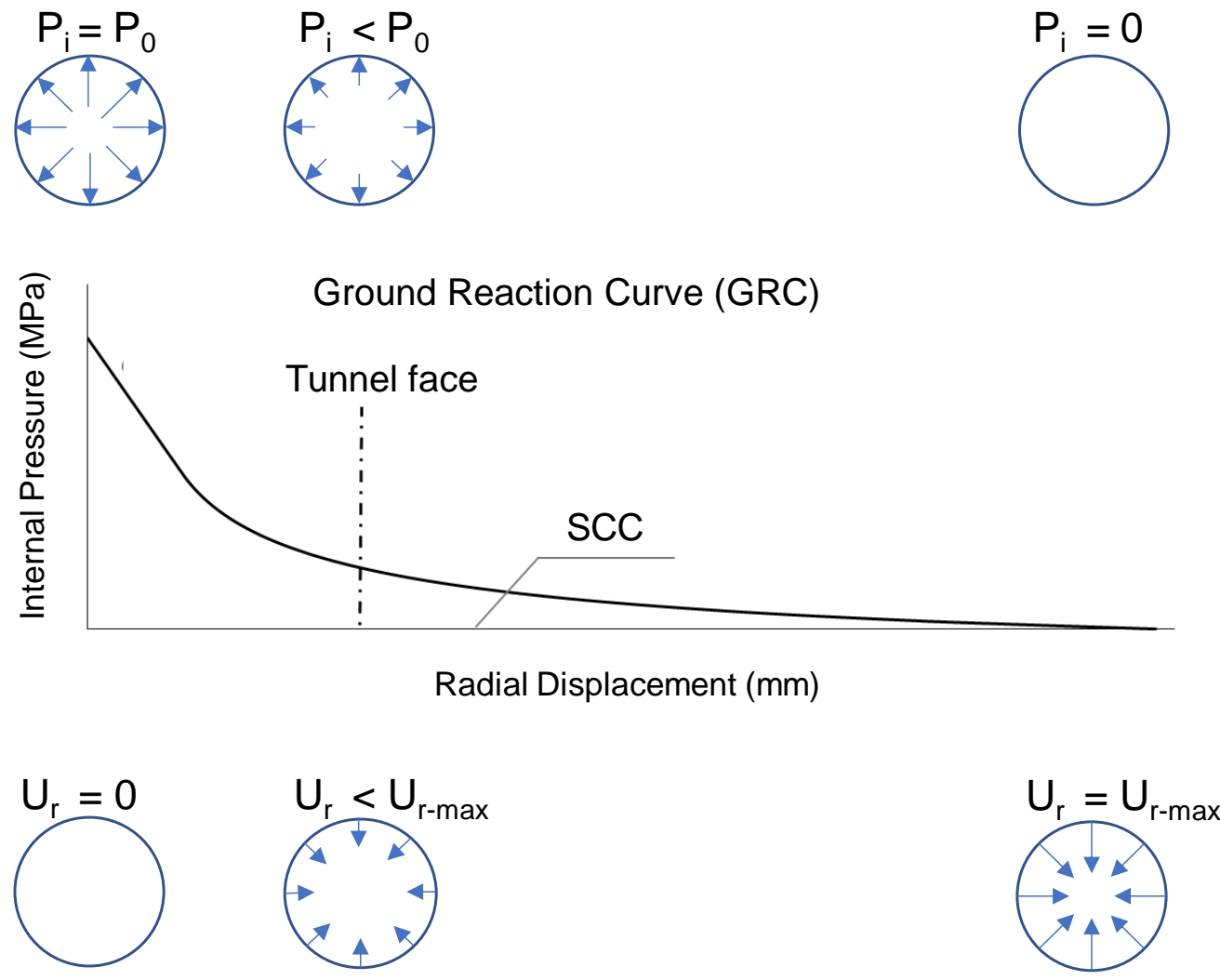

c)

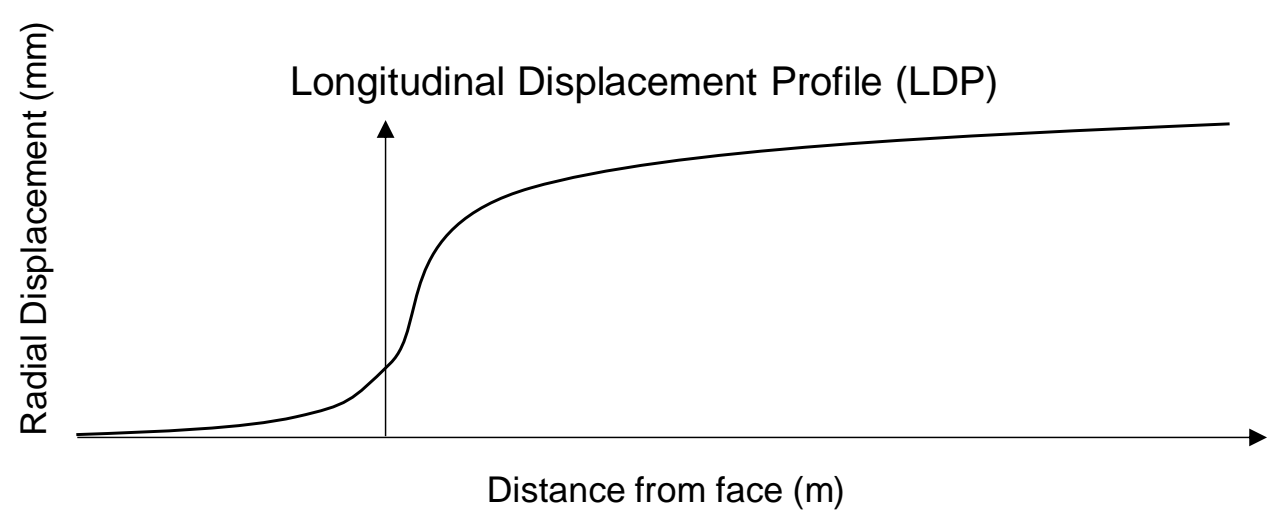

Figure 1 (a) Longitudinal section of an advancing tunnel showing the radial displacement profile and the internal pressures at three sections along the tunnel; (b) Ground reaction curve and support characteristic curve; (c) Longitudinal displacement profile showing the radial displacement at three sections along the tunnel 
Extensive research has been conducted over the past four decades on obtaining the LDP for different ground conditions. Panet \& Guenot (1982) developed one of the earliest methods to calculate the LDP. CarranzaTorres \& Fairhurst (2000) used data from Chern et al. (1998), based on measurements in sedimentary rocks, to develop an empirical equation for the LDP. Unlu \& Gercek (2003) suggested two different equations, one for the displacement ahead of the face and one for behind the face. More recently, Vlachopoulos \& Diederichs $(2009,2014)$ and Oke et al. $(2018)$ used the results of axisymmetric finite element models to develop a series of semi-empirical equations for calculating the LDP.

The SCC represents the stress-strain behaviour of a support element by providing a relationship between the increasing pressure on the support and its corresponding radial displacement (Figure $1 \mathrm{~b}$ ). The SCC consists of two linear sections. The initial section indicates the elastic response of the support element and its maximum capacity. The second section represents the plastic deformation (or strain) of the support element (i.e. post-peak response). By combining the SCC and the GRC, the load Factor of Safety of the support element, which is simply the ratio of the maximum support pressure to the pressure at the intersection point of the GRC and the SCC, can be calculated.

In this paper, the 2D finite element program RS2 (Rocscience 2014) is used to obtain the GRC and determine the plastic radius and maximum radial closure. The semi-empirical approach developed by Vlachopoulos \& Diederichs (2009) is used to obtain the LDP, from which the support installation distance from the face is determined. The stability of the initial shotcrete linings of various thicknesses simulated using structural elements in RS2 is then investigated through analyses of support-capacity diagrams as well as load and strain Factors of Safety in the CCM.

\section{Case study}

In this paper, the methodology proposed for shotcrete lining design is based on a case history reported by Rafiei Renani et al. (2016), who back analysed rock mass properties at an instrumented section of a $10 \mathrm{~m}$ diameter shaft at a depth of $1.2 \mathrm{~km}$. Rafiei Renani et al. (2016) used both 2D and 3D continuum models to simulate the progressive shaft advance and assess the ground convergence. The instrumentation consisted of four multipoint extensometers installed radially at four locations around the shaft boundary at $1 \mathrm{~m}$ behind the shaft face. The magnitudes and orientations of the in-situ stress components for this site obtained from overcoring and hydraulic fracturing techniques are provided in Table 1.

Table 1 The in-situ stress field at the formation (after Rafiei Renani et al. 2016)

\begin{tabular}{lll}
\hline In-situ stress components & Magnitude (MPa) & Orientation \\
\hline Major principal stress & 32 & Vertical \\
Intermediate principal stress & 26 & North-south \\
Minor principal stress & 16 & East-west \\
\hline
\end{tabular}

Figure 2 shows an overview of the shaft advance and the locations of extensometers, shotcrete and concrete liners relative to the shaft bottom. The shaft was excavated using the full-face drill-and-blast method through a sequence consisting of drilling, blasting, ventilation, mucking and support installation, with an advance rate of $3 \mathrm{~m}$ per 24 hours. The initial shotcrete lining was sprayed at $3 \mathrm{~m}$ behind the face, and the final concrete lining was installed at $12 \mathrm{~m}$ behind the face after four rounds of excavation (Figure 2 ). 


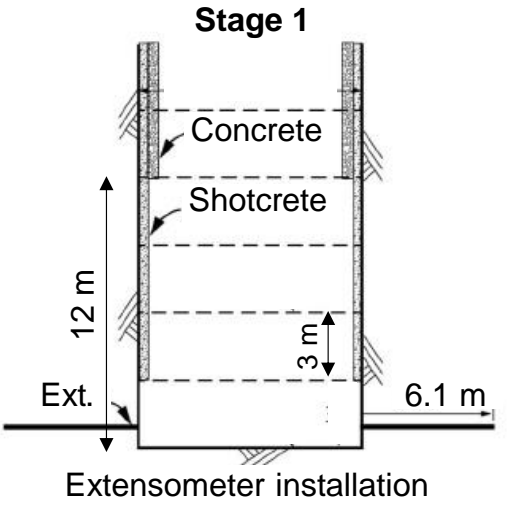

Stage 2

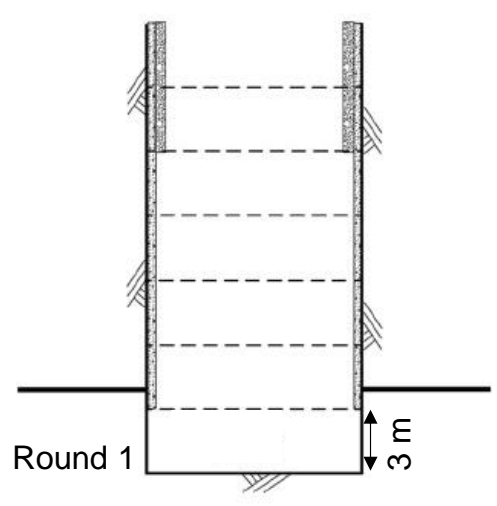

Stage 3

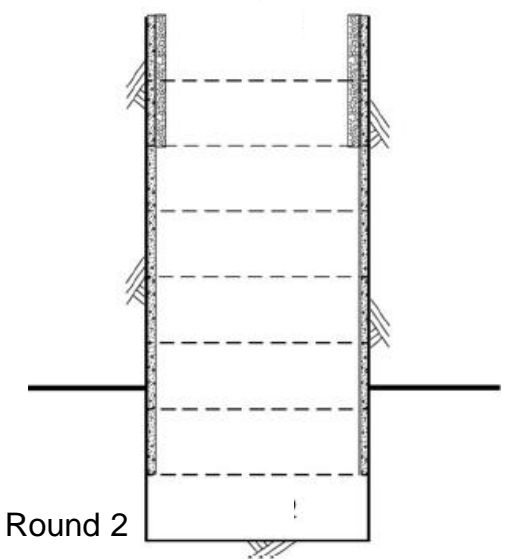

Figure 2 Extensometers and support installation during shaft advance (after Rafiei Renani et al. 2016)

The radial displacements measured from the extensometers after the first and second rounds of excavations are plotted in Figure 3. Rafiei Renani et al. (2016) excluded Extensometer 1 from their analysis because it showed significant scatter when compared with other extensometers (Figure 3a). They back analysed the measured displacements by using the 2D finite element program Phase2 (version 8; Rocscience 2011) and the 3D finite difference program FLAC3D (Itasca 2009). They found that the 3D model that used strain-softening material behaviour did not provide reasonable results whereas the 2D model using elastic-brittle material behaviour had an overall better match to the extensometer data. The calibrated rock mass properties employed by Rafiei Renani et al. (2016) to capture the extensometer measurements using Phase 2 are summarised in Table 2.

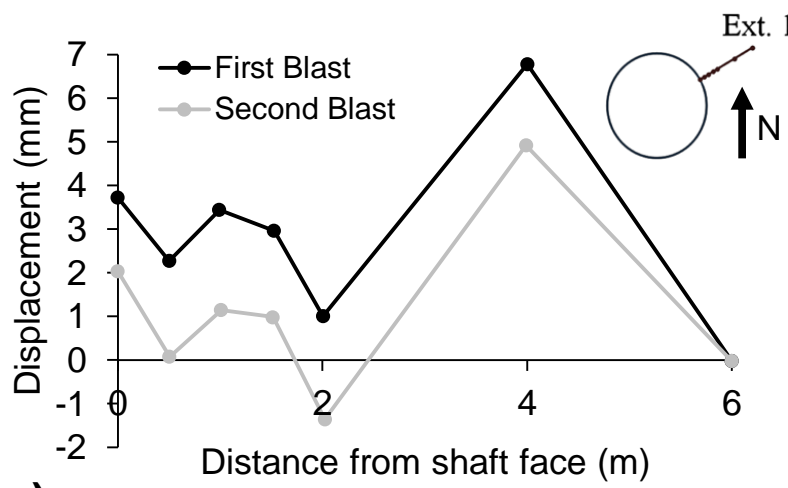

a)

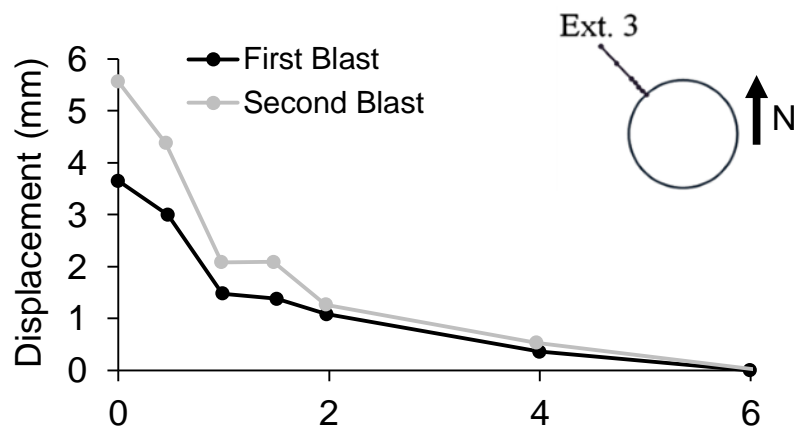

c)

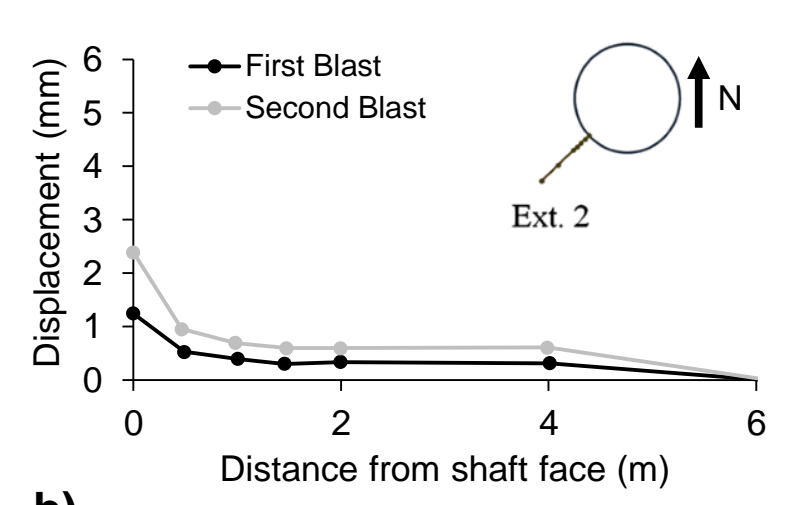

b)

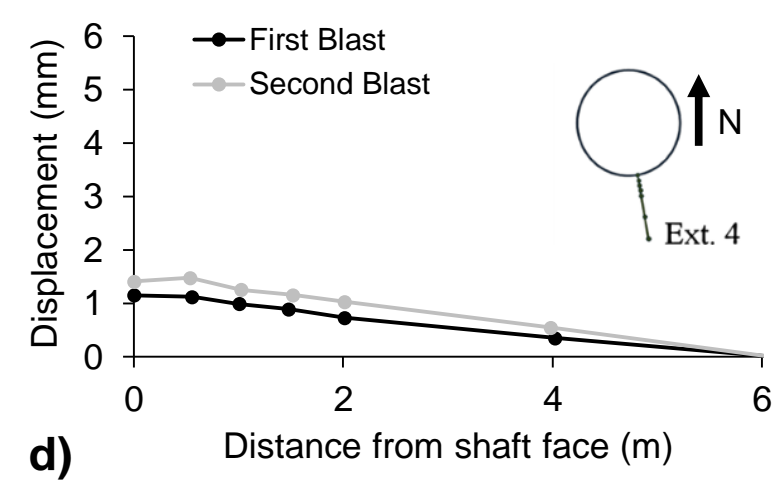

Figure 3 Measured displacements along (a) Extension 1; (b) Extension 2; (c) Extension 3; (d) Extension 4 (after Rafiei Renani et al. 2016) 
Table 1 Calibrated rock mass properties by Rafiei Renani et al. (2016)

\begin{tabular}{ll}
\hline Parameters & Values \\
\hline Young's modulus & $27 \mathrm{GPa}$ \\
Poisson's ratio & 0.25 \\
Peak cohesion & $6 \mathrm{MPa}$ \\
Peak friction angle & $43^{\circ}$ \\
Tensile strength & $2 \mathrm{MPa}$ \\
Residual cohesion & $0.8 \mathrm{MPa}$ \\
Residual friction angle & $41^{\circ}$ \\
Dilation angle & $17^{\circ}$ \\
\hline
\end{tabular}

In the next section, the results of the extensometer measurements in Figure 3 along with the rock mass properties suggested by Rafiei Renani et al. (2016) are adopted to simulate the 3D shaft advance using a 2D continuum model. The stability of the initial shotcrete lining will be evaluated with the aid of support-capacity diagrams as well as analyses of load and strain Factors of Safety.

\section{$4 \quad$ Numerical analyses}

A 2D plane-strain model using the finite element program RS2 (version 9; Rocscience 2014) was used to first simulate the 3D advance of the shaft described above and then to assess the stability of the initial shotcrete lining. The model specifications suggested by Rafiei Renani et al. (2016)-including the model geometry, mesh type and element size-were adopted for this purpose. Figure 4 shows the RS2 model of the $10 \mathrm{~m}$ diameter shaft constructed using a circular external boundary with a diameter of $130 \mathrm{~m}$ (Figure 4a) and four-noded quadrilateral radial mesh elements with a minimum element size of $13 \mathrm{~cm}$ at the excavation boundary (Figure 4b).

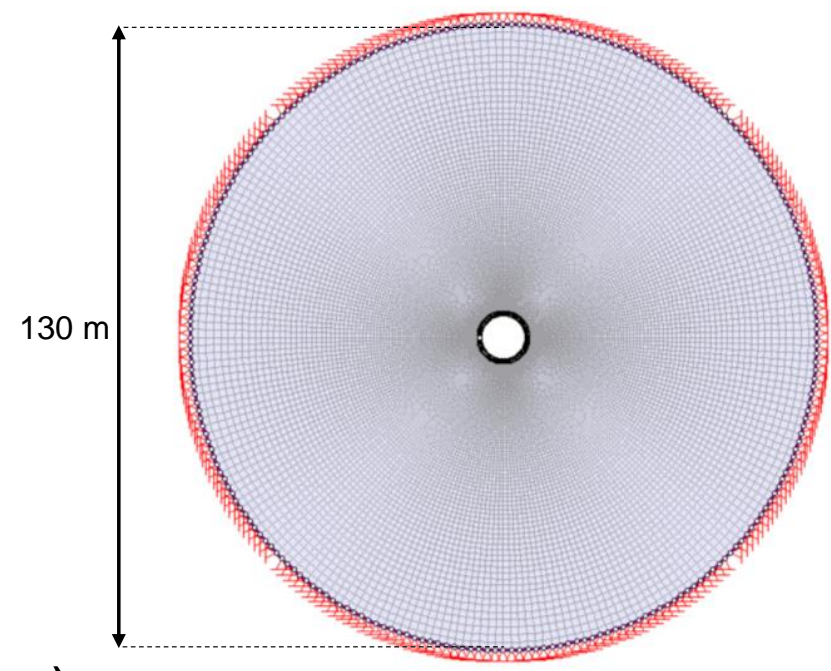

a)

Figure 4 (a) RS2 model geometry; (b) Mesh type and geometry near the simulated shaft

In this study, the internal pressure reduction (i.e. traction relaxation) approach was used to simulate the 3D shaft advance as opposed to the core replacement (i.e. core softening) approach used by Rafiei Renani et al. (2016). According to Vlachopoulos \& Diederichs (2014), the results of the internal pressure reduction (IPR) approach is less dependent on the size and type of mesh elements and the number of stages than is the replacement approach. Moreover, it is possible to make a direct comparison between the GRC obtained from 
the IPR approach and that of analytical solutions (e.g. Carranza-Torres \& Fairhurst 2000; Carranza-Torres 2004). In the IPR approach, an internal pressure with magnitudes and orientations respectively equal and opposite to the in-situ stresses is applied to the excavation boundary during the first modelling stage. The magnitude of internal pressure is gradually reduced in the subsequent stages until it reaches zero in the last stage, at which the maximum radial displacement corresponding to a distance far from the shaft face occurs. The GRC is then obtained by plotting the internal pressure as a function of radial displacement of a point on the excavation boundary.

\subsection{Model calibration}

Initial numerical simulations were conducted using the rock mass properties back calculated by Rafiei Renani et al. (2016). However, the results in terms of the depth of yielding and the displacements along the extensometers were slightly different from those reported by Rafiei Renani et al. (2016). Therefore, a series of sensitivity analyses were conducted on the residual rock mass strength parameters (i.e. residual cohesion and residual friction angle) and the dilation angle. It was found that by using a dilation angle of $13^{\circ}$ instead of $17^{\circ}$ and the peak and residual rock mass strength properties used by Rafiei Renani et al. (2016) (listed in Table 2), it is possible to capture the extensometer measurements. The reason for the difference between the results of the two models is not known. This minor difference may be related to the use of different versions of the finite element program (i.e. Phase2 version 8 by Rafiei Renani et al. [2016], versus RS2 version 9 in this study) and the different shaft advance simulation methods (i.e. core softening approach by Rafiei Renani et al. [2016] versus IPR approach in this study).

Figure 5 shows the GRC and the shape and extent of the yielded zone around the shaft obtained from the calibrated model. As can be seen from this figure, the maximum and minimum plastic radii are $8.3 \mathrm{~m}$ and $6.6 \mathrm{~m}$, respectively. Note that the GRC in Figure 5 was plotted from a point on the excavation boundary with a maximum radial displacement of $22 \mathrm{~mm}$. By using the LDP equations developed by Vlachopoulos \& Diederichs (2009), the radial displacement corresponding to the shaft face was determined to be $5.7 \mathrm{~mm}$, as indicated on the GRC plot in Figure 4.

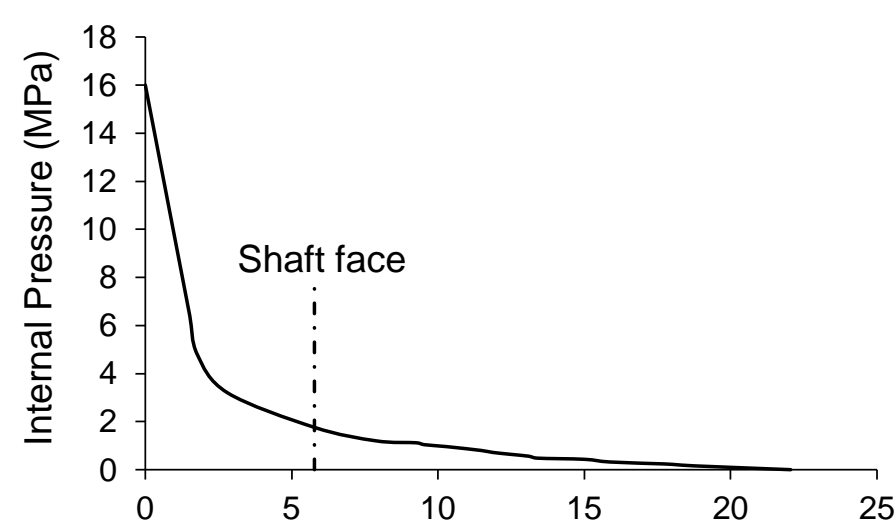

a)

Figure 5 (a) Ground reaction curve obtained from RS2 model; (b) Yielded zone predicted using calibrated numerical model

The radial displacements measured along the extensometers and those obtained from the calibrated model are compared in Figure 6. This figure shows a good agreement between the results of field measurements and numerical simulations for Extensometers 3 and 4. However, the calibrated model in this study overestimates the displacements for Extensometer 2 by a factor of about 2 at the excavation boundary. The simulated displacements along extensometers presented in Figure 6 match those obtained by Rafiei Renani et al. (2016). 

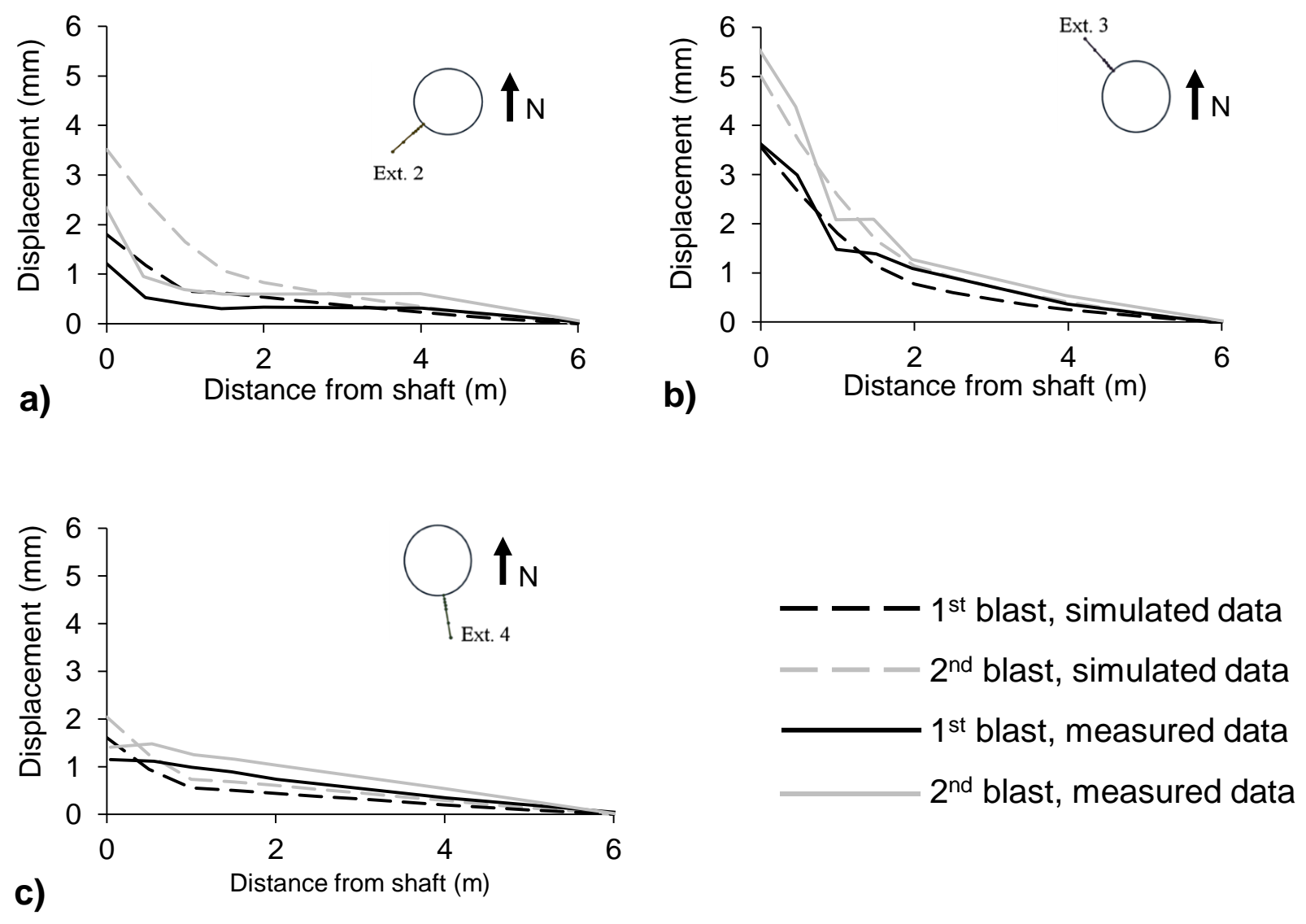

Figure 6 Comparison of measured and simulated displacements along (a) Extension 2; (b) Extension 3; (c) Extension 4

\subsection{Shotcrete properties}

Once the numerical model had been calibrated, it was used to simulate the ground support and analyse its stability. As mentioned earlier, the support system for the shaft consisted of an initial shotcrete lining sprayed at $3 \mathrm{~m}$ behind the face and a final concrete lining installed at $12 \mathrm{~m}$ behind the face after four rounds of excavations. No information on the specifications and properties of the shotcrete lining is available. Therefore, existing empirical equations were used to estimate its mechanical properties as a function of their age.

The initial shotcrete liner was sprayed in the last step of the excavation sequence (i.e. drilling, blasting, ventilation, mucking and shotcrete). In accordance with Rafiei Renani et al. (2016), the shaft advance length was $3 \mathrm{~m}$, and every round took about 24 hours. The exact time between the installation of the initial shotcrete lining and the next round of the blast is not known. It was assumed that blasting took place 12 hours after the initial shotcrete was sprayed. This means that the shotcrete hardened over a period of 12 hours before it was loaded due to the next $3 \mathrm{~m}$ shaft advance. As such, the properties of 12 -hour shotcrete were used to account for the shaft advance rate of $3 \mathrm{~m}$ per excavation round. Note that due to the excavation advance, no attempt was made to simulate changes in the properties of the shotcrete over time.

Several empirical relationships have been proposed for the mechanical properties of shotcrete as a function of age (e.g. Carranza-Torres \& Fairhurst 2000; Chang 1994; Comité Euro-International du Béton \& Fédération Internationale de la Précontrainte [CEB FIP] 1990; Meschke et al. 1996). The change in the compressive strength and the Young's modulus of shotcrete over time is illustrated in Figure 7. These relationships, along with those for Poisson's ratio and tensile strength by Carranza-Torres \& Fairhurst (2000) and Meschke et al. (1996), were used to estimate the properties of the 12-hour shotcrete lining. Table 3 summarises the mechanical properties of the initial shotcrete lining used in the numerical simulations. 


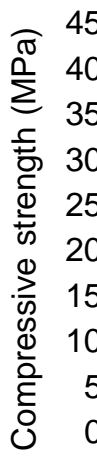

a)

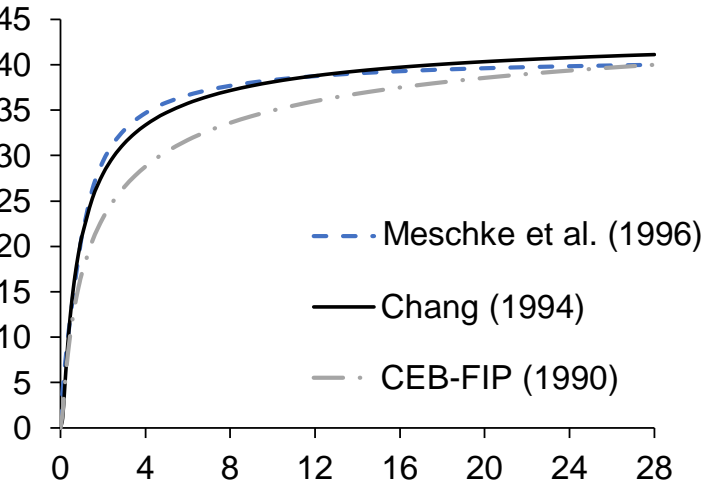

Shotcrete age (days)

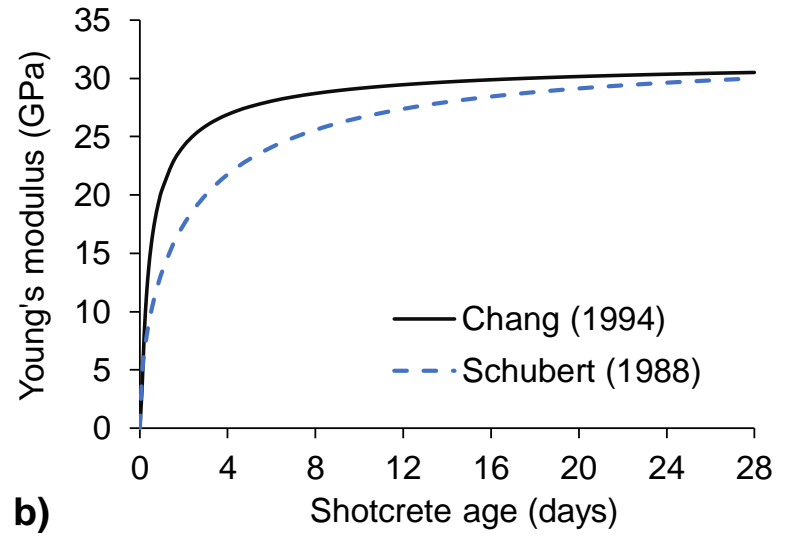

Figure 7 (a) Compressive strength; (b) Young's modulus of shotcrete as a function age (days)

Table 3 Properties of 12-hour shotcrete used in numerical models

\begin{tabular}{ll}
\hline Properties & 12-hour shotcrete \\
\hline Young's modulus & $12 \mathrm{GPa}$ \\
Compressive strength & $13.2 \mathrm{MPa}$ \\
Tensile strength & $1.36 \mathrm{MPa}$ \\
Poisson's ratio & 0.25 \\
\hline
\end{tabular}

\subsection{Support-capacity diagrams for initial shotcrete lining}

The initial lining was simulated using the built-in structural element in RS2 and with the properties listed in Table 3. Combining the GRC (Figure 5a) and the LDP (Vlachopoulos \& Diederichs 2009) allowed for the determination of radial displacements corresponding to the location of shotcrete lining with respect to the shaft face. A series of sensitivity analyses were conducted to evaluate the influence of lining thickness on the stability of lining in response to the shaft advance and consequent wall deformation using the support-capacity diagrams. Analyses were conducted for initial shotcrete lining thicknesses of 50,75 and $100 \mathrm{~mm}$.

The support-capacity diagram provides a method for determining the Factor of Safety for a liner. For a given Factor of Safety, capacity envelopes are plotted in axial force (thrust) versus moment and axial force versus shear force. Values of thrust, moment and shear force are then calculated for all the segments along the structural element representing the liner and compared with the capacity envelopes. If the calculated thrust-moment or thrust-shear force values fall inside the relevant envelope, they have a Factor of Safety greater than the envelope's value. The calculation of thrust, moment and shear force values for the liner elements in RS2 is based on the methodology proposed by Carranza-Torres \& Diederichs (2009).

Figure 8 shows thrust-moment diagrams calculated for Factors of Safety of 1.0 (black envelope) and 1.4 (grey envelope) for initial shotcrete lining thicknesses of $50 \mathrm{~mm}$ (Figure 8a), $75 \mathrm{~mm}$ (Figure 8b) and $100 \mathrm{~mm}$ (Figure 8c). The segments of structural elements with Factors of Safety of less than 1 (i.e. points outside the black envelopes) are highlighted in red in Figures $8 b, 8 d$ and $8 f$. As shown in these figures, the induced axial forces are sufficient to exceed the capacity of the shotcrete lining for several segments along the structural element on the right and left sides of the shaft wall. This is interpreted to be due to high tangential stresses on the east and west sides of the shaft resulting in extensive rock mass yielding, as shown in Figure $5 \mathrm{~b}$. 

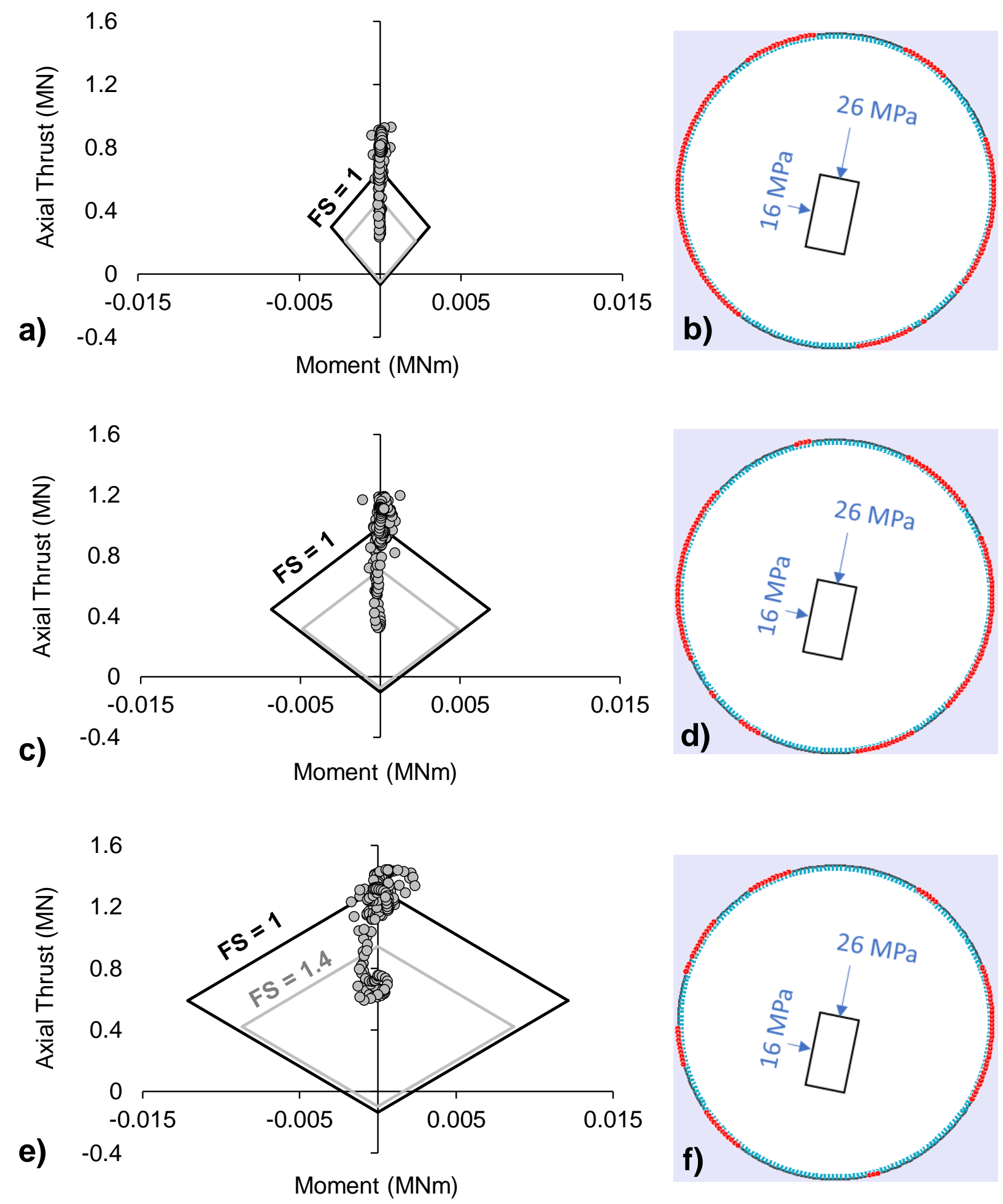

Figure 8 Thrust-moment diagrams and overloaded sections of initial shotcrete lining (red segments) with thicknesses of (a) and (b) $50 \mathrm{~mm}$; (c) and (d) $75 \mathrm{~mm}$; (e) and (f) $100 \mathrm{~mm}$

The results of the sensitivity analyses presented in Figure 8 demonstrate how an increase in the lining thickness increases the Factor of Safety and reduces overloaded lengths of the liner. This was further investigated by calculating the percentage of the liner segments having a Factor of Safety of less than unity for various lining thicknesses. It was found that $60 \%$ of the segments are overloaded (i.e. FS $<1$ ) for the initial shotcrete lining with a thickness of $50 \mathrm{~mm}$. The percentages of segments with Factors of Safety of less than unity decrease to about $51 \%$ and $37 \%$ for shotcrete lining thicknesses of $75 \mathrm{~mm}$ and $100 \mathrm{~mm}$, respectively. 
The results of analyses presented in this section indicate that overloading of initial shotcrete lining seems to be inevitable. However, overloading does not necessarily imply complete failure. It is known that early-age shotcrete behaves in an elastoplastic manner (John \& Mattle 2003). The stability of initial shotcrete may not be of great concern if its overloading results in minor cracking because early-age shotcrete can maintain the load and experience large amounts of plastic deformation before failure occurs. In the next section, a methodology is proposed based on the strain Factor of Safety for shotcrete lining to analyse its stability during the excavation advance.

\section{$5 \quad$ Strain Factor of Safety for initial shotcrete lining}

The load Factor of Safety ( $\mathrm{FS}_{\mathrm{load}}$ ) for support has been traditionally determined from the analysis of the GRC and the SCC. Figure 9a shows a $\mathrm{FS}_{\text {load }}$ greater than 1. In this figure, the $\mathrm{FS}_{\text {load }}$ is the ratio between the maximum support pressure $\left(P_{s}\right)$ and the equilibrium pressure $\left(P_{e}\right)$, which is the pressure at the intersection point of the GRC and the SCC. By knowing the plastic deformation of shotcrete lining, it is also possible to calculate a strain Factor of Safety for the support. The strain Factor of Safety is the ratio of the plastic strain of the shotcrete $\left(\mathrm{S}_{\mathrm{s}}\right)$ to the equilibrium strain $\left(\mathrm{S}_{\mathrm{e}}\right)$, which is the plastic strain up to the intersection point of the GRC and the SCC. A FS strain greater than 1 is calculated as shown in Figure 9b. The application of the strain Factor of Safety is for the design of the initial shotcrete lining, where the shotcrete is young and behaves in a ductile manner.

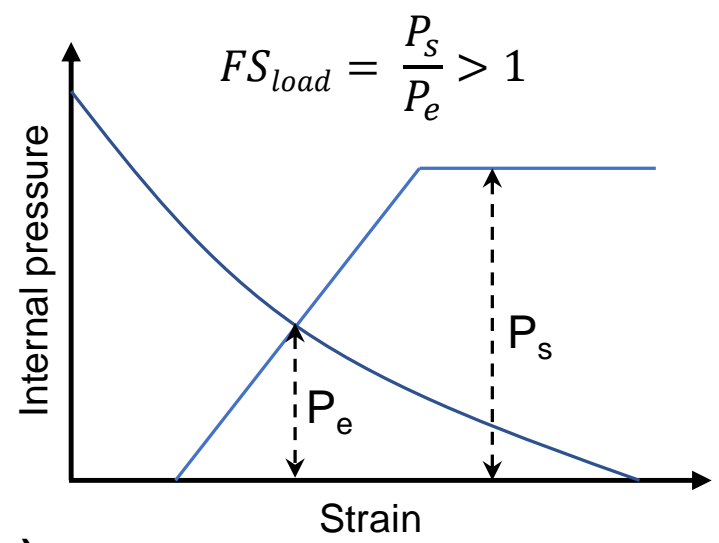

a)

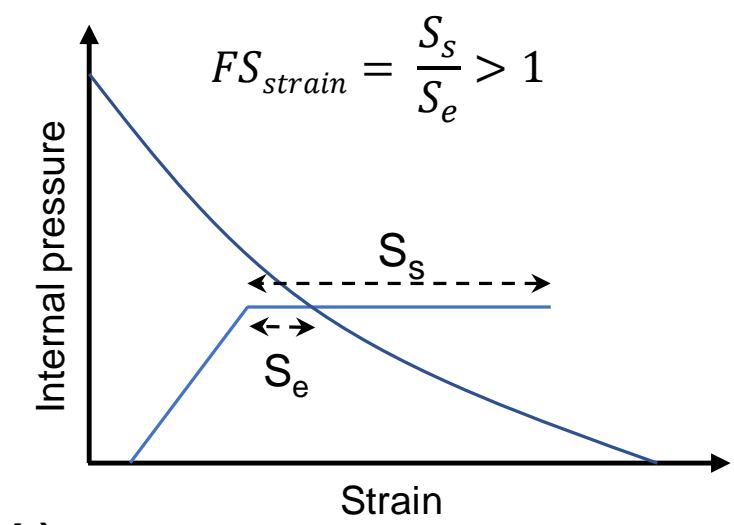

b)

Figure 9 Definitions of (a) Load Factor of Safety (FS Ioad) greater than 1; (b) Strain Factor of Safety (FS strain) greater than 1 
The conceptual deformation of shotcrete lining due to the shaft wall convergence is illustrated in Figure 10. This figure shows that the shotcrete lining deforms towards the centre of the shaft (i.e. in the radial direction) due to the internal compressive stresses that develop in response to the shaft advance and consequent wall convergence. Therefore, the lateral plastic strain of shotcrete lining-as opposed to the axial plastic strainshould be used for the calculation of the strain Factor of Safety.

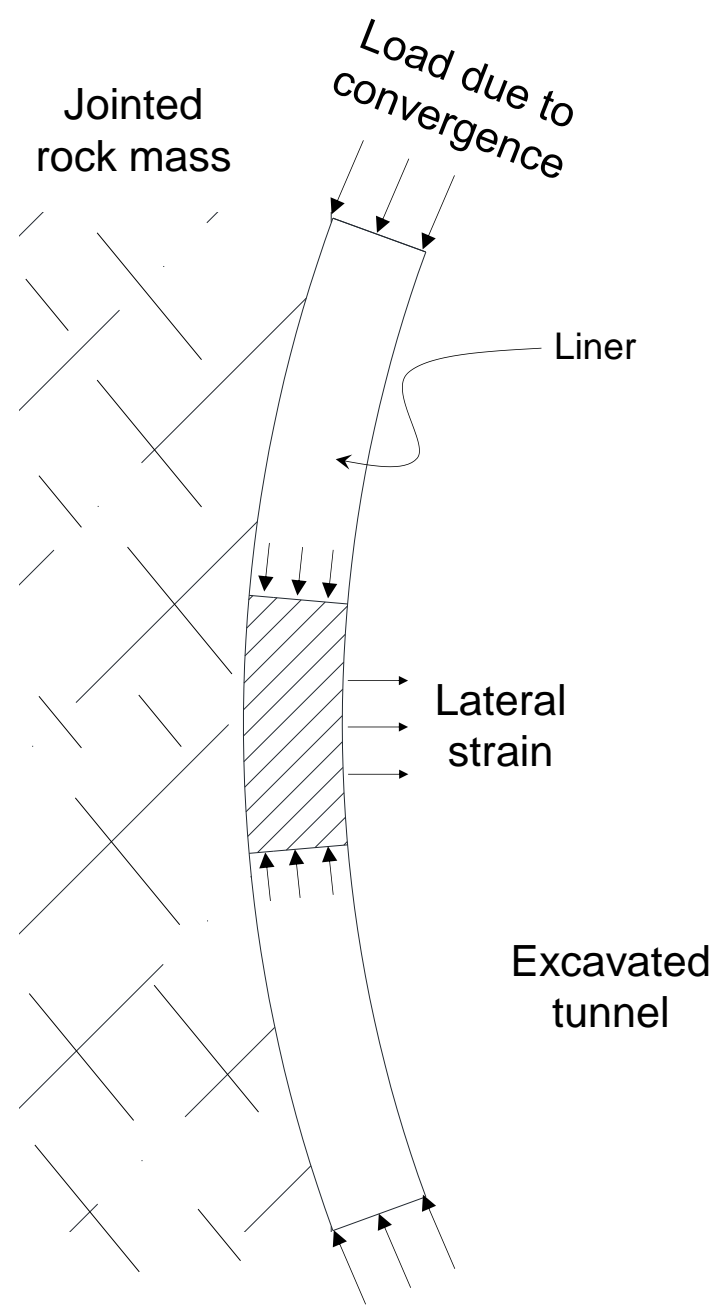

Figure 10 Schematic radial deformation of shotcrete lining due to shaft wall convergence

In order to calculate the strain Factor of Safety for the initial shotcrete lining, a relationship between the shotcrete lateral plastic strain and its age must be developed. Unfortunately, laboratory test data on the lateral strain of shotcrete as a function of shotcrete age are scarce. In this paper, the results of laboratory uniaxial compressive tests on steel-fibre-reinforced shotcrete reported by Saw et al. (2009) were used. Figure 11a presents the stress-strain curves for different shotcrete curing times (i.e. 1 day, 3 days, 7 days and 28 days). The test results show that the yield point and the peak stress increase with the curing time. After the yield point, non-linear strain hardening is observed until the peak strength is reached. Following the peak point, strain softening and/or sudden stress drop occurs, indicating brittle failure. The axial plastic strain seems to be independent of the shotcrete age. However, the lateral plastic strain increases along with the shotcrete age.

The stress-strain curves shown in Figure 11a were used to develop a relationship between the lateral plastic strain and the shotcrete age (curing time). The lateral plastic strain is calculated from the strain difference between the peak stress and the stress drop. An example of the lateral plastic strain for the 28-day shotcrete is presented in Figure 11a. The plot of lateral plastic strain versus the shotcrete age is provided in Figure 11b. 
The following logarithmic function was used to fit to the data:

$$
\varepsilon_{l p}=0.1 \ln (t)+0.4
$$

where:

$$
\begin{aligned}
& \varepsilon_{1 p}=\text { the lateral plastic strain (\%) } \\
& t=\text { the age of shotcrete (days) }
\end{aligned}
$$

Using Equation 1, the lateral plastic strain for the 12 -hour shotcrete is estimated to be $0.33 \%$. By plotting the GRC from the calibrated numerical model and the SCC for the initial $50 \mathrm{~mm}$ shotcrete lining, the $\mathrm{FS}_{\text {load }}$ and $\mathrm{FS}_{\text {strain }}$ were calculated, and the results are presented in Figure 12.
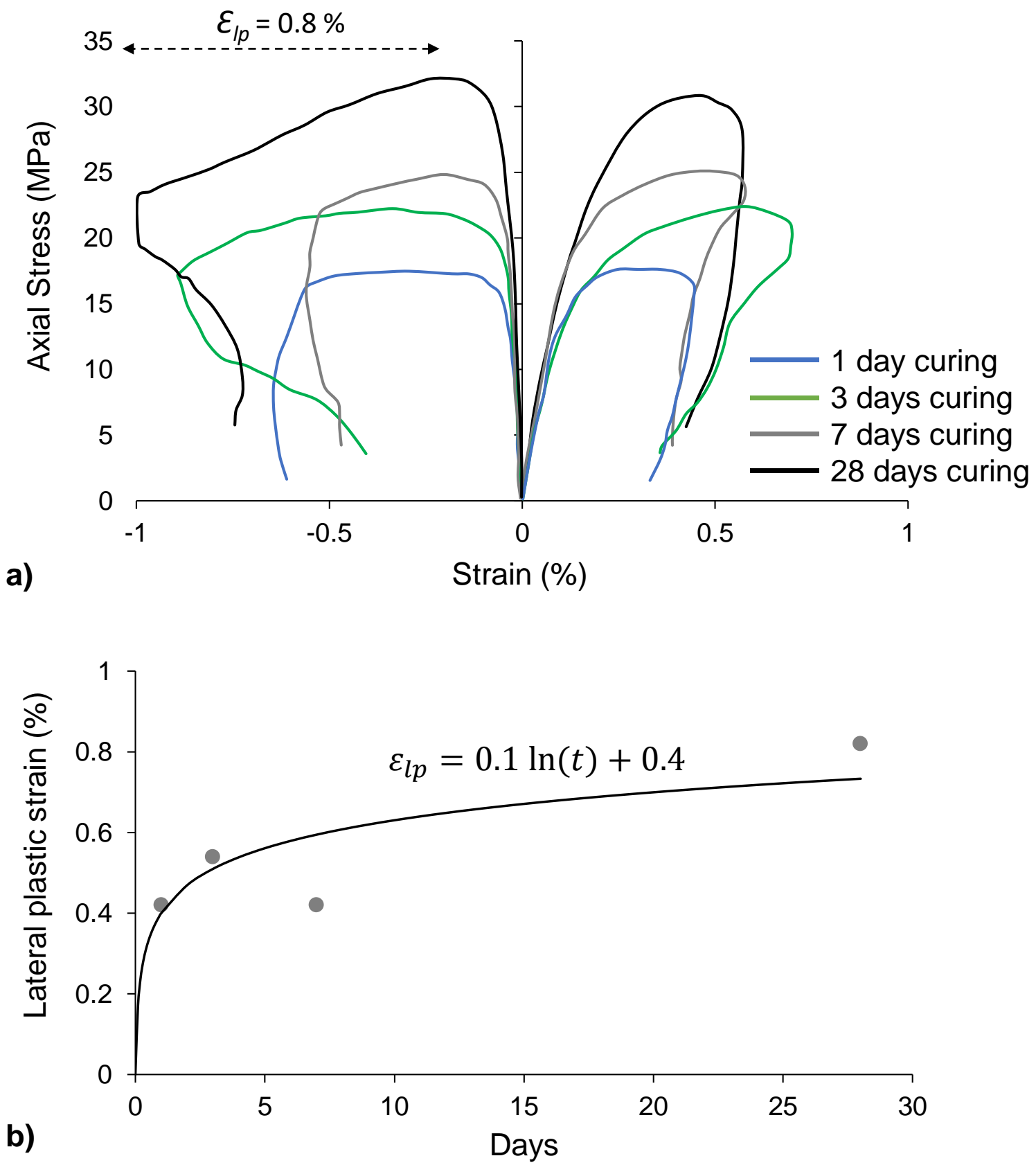

Figure 11 (a) Shotcrete stress-strain curves obtained from UCS tests for different curing times (after Saw et al. 2009); (b) Best-fit line relating plastic lateral strain to shotcrete age 


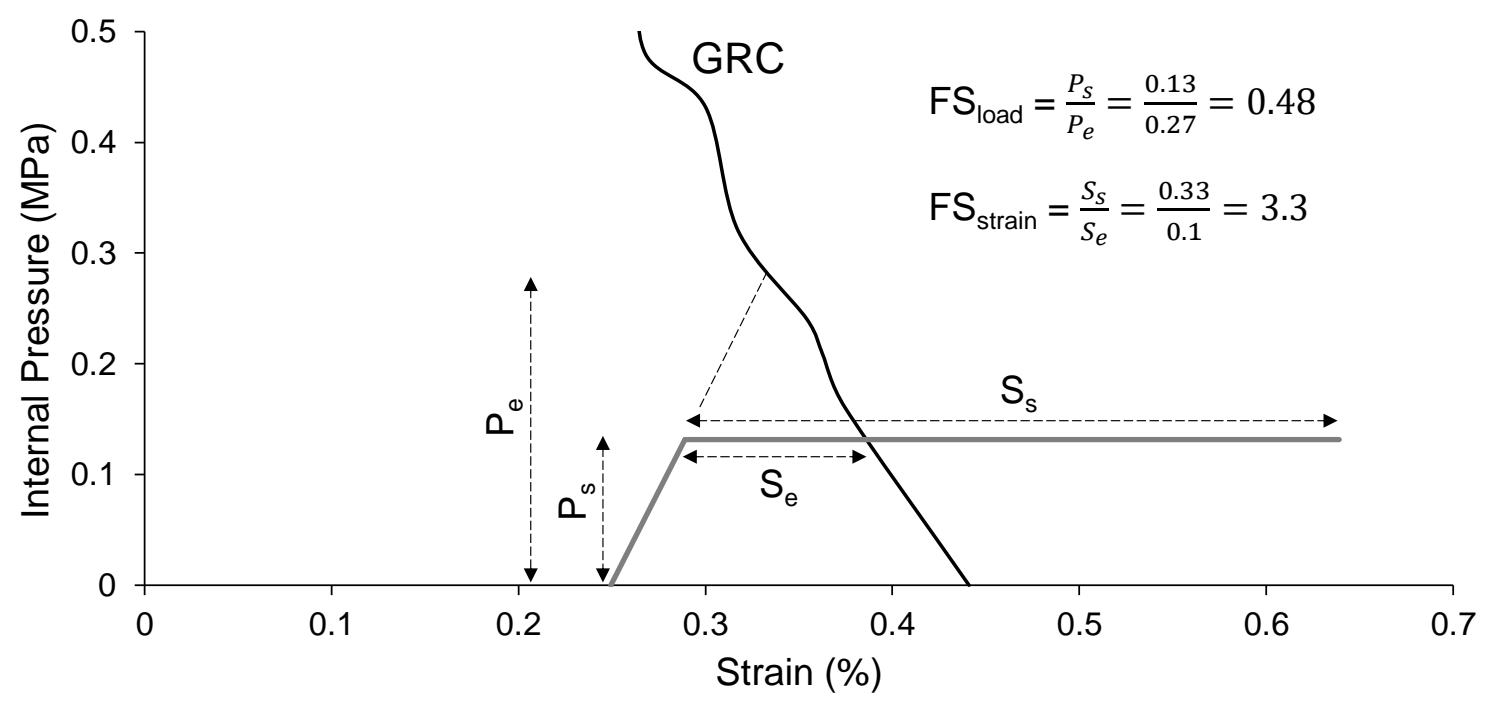

Figure 12 Load Factor of Safety ( $\left.\mathrm{FS}_{\mathrm{load}}\right)$ and strain Factor of Safety $\left(\mathrm{FS}_{\text {strain }}\right)$ calculated for $50 \mathrm{~mm}$ initial shotcrete lining

The load and strain Factors of Safety calculated for various shotcrete thicknesses are compared in Table 4. Although the load Factor of Safety is less than unity for all shotcrete thicknesses, the strain Factors of Safety are well above 1 . This means that even the $50 \mathrm{~mm}$ shotcrete lining can be used as initial lining because it can maintain the load during the shaft advance and wall convergence until the final concrete lining is installed.

Table 4 Comparison between load Factor of Safety ( $\left.\mathrm{FS}_{\text {load }}\right)$ and strain Factor of Safety $\left(\mathrm{FS}_{\text {strain }}\right)$ for different shotcrete thicknesses

\begin{tabular}{lll}
\hline Shotcrete thickness $(\mathbf{m m})$ & $\mathbf{F S}_{\text {load }}$ & FS $_{\text {strain }}$ \\
\hline 50 & 0.48 & 3.3 \\
75 & 0.60 & 4.5 \\
100 & 0.68 & 6.6 \\
\hline
\end{tabular}

Based on the analyses presented in this section, it is suggested that both load and strain Factors of Safety should be considered in the design of initial shotcrete lining. Support-capacity diagrams should also be used to determine Factors of Safety for thrust and shear forces as well as bending moments for different segments of the liner along the periphery of the excavation. The combination of all these methods provides a deeper insight into the complex behaviour of shotcrete lining due to excavation advance.

\section{Summary and conclusion}

The 2D finite element program RS2 was used to simulate the 3D excavation advance of an instrumented section of a shaft at a depth of $1.2 \mathrm{~km}$. The initial shotcrete lining was simulated using the built-in structural element in RS2. The information about the shaft advance rate allowed for the determination of the appropriate mechanical properties of the initial shotcrete lining. Three methods were used to assess the stability of the initial lining. The first method was based on the analysis of support-capacity diagrams. For this purpose, thrust-moment diagrams were plotted for initial linings with thicknesses of $50 \mathrm{~mm}, 75 \mathrm{~mm}$ and $100 \mathrm{~mm}$. This method allowed for the determination of overloaded sections of the liner. In the second method, the load Factor of Safety was calculated using the conventional CCM. In the third method, the GRC and the SCC of the shotcrete were used to calculate a strain Factor of Safety for the initial shotcrete lining. The strain Factor of Safety is defined as the ratio between the plastic radial strain of the shotcrete and the equilibrium strain, which is the shotcrete plastic radial strain at the intersection point of the GRC and the 
SCC. The comparison of the three methods showed that although the load Factors of Safety for the liner obtained from the analyses of the support-capacity diagram and the conventional CCM are less than 1, the strain Factor of Safety for all lining thicknesses is well above 1. It is therefore suggested that the minimum allowable shotcrete thickness for initial lining be $50 \mathrm{~mm}$.

The strain Factor of Safety for the design of initial shotcrete lining was determined based on laboratory tests on 1-day, 3-day, 7-day and 28-day shotcrete. The calculation of strain Factor of Safety for the shaft case study presented in this paper required obtainment of the lateral plastic strain of a 12-hour shotcrete. Therefore, the best-fit curve through the lab test data was used to extrapolate the lateral plastic strain for the 12-hour shotcrete. It should be noted that depending on the temperature of the rock (inertial temperature) and the Blaine of the cement, the material between the time of spraying and the next few hours is not concrete/shotcrete but ettringite. In this respect, it is suggested that further laboratory experiments be conducted to obtain the properties of early-age shotcrete (i.e. $<1$ day), especially axial and lateral plastic strains. Furthermore, a more realistic design should consider the excavation cycle with respect to the shotcrete curing rate. This was beyond the scope of this paper but will be considered in future studies.

It should be emphasised that the details of the support design for the shaft case study-such as the type, thickness and properties of shotcrete lining-were not available to the authors. Therefore, the analyses presented in this paper were based on engineering judgement, assumptions and information obtained from various sources in the literature. Thus, the conclusion drawn from the results of this investigation should remain within the bounds and limitations outlined in this paper.

\section{Acknowledgement}

A deeper understanding of shotcrete lining design for fast advancing excavations has been obtained through many discussions with Peter K Kaiser and Sean Maloney. This research was supported by the Natural Sciences and Engineering Research Council of Canada and Dalhousie University.

\section{References}

Carranza-Torres, C 2004, 'Elasto-plastic solution of tunnel problems using the generalized form of the Hoek-Brown failure criterion', International Journal of Rock Mechanics and Mining Sciences, vol. 13, no. 3, pp. 629-639.

Carranza-Torres, C \& Diederichs, M 2009, 'Mechanical analysis of circular liners with particular reference to composite supports. For example, liners consisting of shotcrete and steel sets', Tunnelling and Underground Space Technology, vol. 24, no. 5, pp. 506-532.

Carranza-Torres, C \& Fairhurst, C 2000, 'Application of the convergence-confinement method of tunnel design to rock masses that satisfy the Hoek-Brown failure criterion', Tunnelling and Underground Space Technology, vol. 15, no. 2, pp. 187-213.

Chang, Y 1994, Tunnel Support with Shotcrete in Weak Rock: A Rock Mechanics Study, PhD thesis, Royal Institute of Technology, Stockholm, Sweden.

Chern, JC, Shiao, FY \& Yu, CW 1998, 'An empirical safety criterion for tunnel construction', Proceedings of the Regional Symposium on Sedimentary Rock Engineering, Public Construction Commission, Taipei, pp. 222-227.

Comité Euro-international du Béton \& Fédération Internationale de la Précontrainte 1990, CEB-FIP Model Code 1990: Design Code, Thomas Telford, London.

Duncan Fama, ME 1993, 'Numerical modelling of yield zones in weak rock', in JA Hudson (ed.), Comprehensive Rock Engineering, 2, Pergamon, Oxford, pp. 49-75.

Gschwandtner, GG \& Galler, R 2012, 'Input to the application of the convergence confinement method with time-dependent material behaviour of the support', Tunnelling and Underground Space Technology, vol. 27, no. 1, pp. 13-22.

Itasca 2009, FLAC3D, version 3.3, Itasca, Minneapolis.

John, M \& Mattle, B 2003, 'Shotcrete lining design: Factors of influence', Proceedings of Rapid Excavation and Tunnelling Conference (RETC), Society for Mining Metallurgy and Exploration, Englewood, pp. 726-734.

Meschke, G, Kropik, C \& Mang, H 1996, 'Numerical analysis of tunnel linings by means of a viscoplastic material model for shotcrete', International Journal for Numerical Methods in Engineering, vol. 39, no. 18, pp. 3145-3162.

Oke, J, Vlachopoulos, N \& Diederichs, MS 2018, 'Improvement to the convergence-confinement method: inclusion of support installation proximity and stiffness', Rock Mechanics and Rock Engineering, vol. 51, no. 5, pp. 1495-1519, https://doi.org/ 10.1007/s00603-018-1418-0.

Oreste, P 2003, 'A procedure for determining the reaction curve of shotcrete lining considering transient conditions', Rock Mechanics and Rock Engineering, vol. 36, no. 3, pp. 209-236.

Oreste, P \& Pelia, D 1997, 'Modelling progressive hardening of shotcrete in convergence-confinement approach to tunnel design' Tunnelling and Underground Space Technology, vol. 12, no. 3, pp. 425-431. 
Panet, M \& Guenot, A 1982, 'Analysis of convergence behind the face of a tunnel', Proceedings of the International Symposium Tunnelling, Institution of Mining and Metallurgy, London, pp. 197-204.

Rafiei Renani, H, Martin, C \& Hudson, R 2016, 'Back analysis of rock mass displacements around a deep shaft using two- and three-dimensional continuum modelling', Rock Mechanics and Rock Engineering, vol. 49, no. 4, pp. 1313-1327.

Rispin, M, Kleven, OB, Dimmock, R \& Myrdal, R 2017, 'Shotcrete: early strength and re-entry revisited - practices and technology', in M Hudyma \& Y Potvin (eds), Proceedings of the First International Conference on Underground Mining Technology, Australian Centre for Geomechanics, Perth, pp. 55-70.

Rocscience 2011, Phase2, version 8, computer software, Rocscience, Toronto.

Rocscience 2014, RS2, version 9, computer software, Rocscience, Toronto.

Saw, HA, Villaescusa, E, Windsor, CR \& Thompson, AG 2009, 'Non-linear elastic - plastic response of steel fibre reinforced shotcrete to uniaxial and triaxial compression testing', Proceedings of Shotcrete for Underground Support XI, Engineering Conferences International, Davos.

Schubert, P 1988, 'Beitrag zum rheologischen Verhalten von Spritzbeton', Felsbau, vol. 6, no. 3, pp. 150-153.

Unlu, T \& Gercek, H 2003, 'Effect of Poisson's ratio on the normalized radial displacements occurring around the face of a circular tunnel', Tunnel and Underground Space Technology, vol. 18, no. 5, pp. 547-553.

Vlachopoulos, N \& Diederichs, MS 2009, 'Improved longitudinal displacement profiles for convergence confinement analysis of deep tunnels', Rock Mechanics and Rock Engineering, vol. 42, no. 2, pp. 131-146.

Vlachopoulos, N \& Diederichs, MS 2014, 'Appropriate uses and practical limitations of 2D numerical analysis of tunnels and tunnel support response', Geotechnical and Geological Engineering, vol. 32, no. 2, pp. 469-488. 